\title{
Science from Genes to Landscapes
}

Wherever flowering plants flourish, pollinating bees, birds, butterflies, bats, and other animals are at work, providing vital and often unnoticed services. Many of these species are in serious decline, a situation if unabated, threatens agricultural production, maintenance of natural plant communities, and other important services. Responding to this urgent challenge, the U.S. Geological Survey (USGS) is part of efforts to provide scientific information to support pollinator conservation, including the implementation of a national pollinator health strategy ${ }^{1}$.

This science is but one example of how the Ecosystems Science Mission Area of the USGS conducts science to support sound management and conservation of our Nation's biological resources. It does this through research, technical assistance, and education conducted by Cooperative Research Units and Science Centers located in nearly every State.

The quality of life and economic strength in America hinges on healthy ecosystems that support living things and natural processes. Ecosystem science better enables society to understand how and why ecosystems change, to predict and forecast future changes, and to guide actions that can prevent damage to, and restore and sustain ecosystems. It is through this knowledge that informed decisions are made about natural resources that can enhance our Nation's economic and environmental well-being.

\section{Ecosystems Focal Areas and Examples of USGS Science}

Today the Ecosystems Science Mission Area concentrates its research in eight areas that address modern ecological and social issues and the interests of public and private groups.

\section{Species of Concern}

Developing the knowledge base and tools to assess, conserve, and restore species of concern.

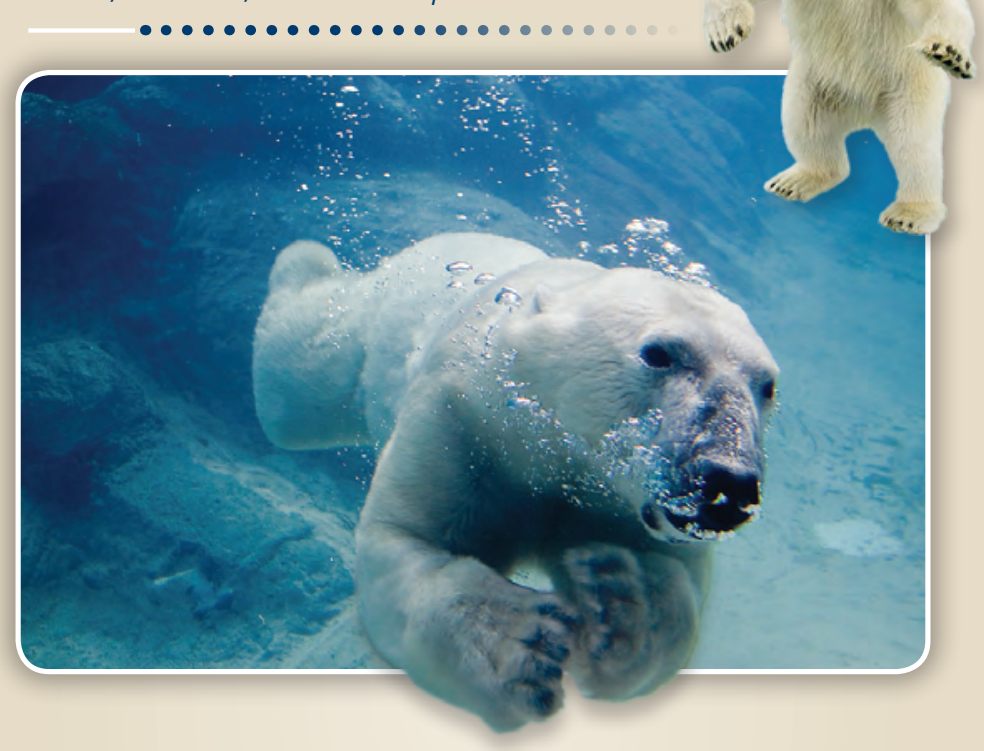

The USGS conducts research on species of concern to Federal land- and resource-management agencies. These include federally threatened, endangered, and candidate species; marine mammals; and inter-jurisdictional and migratory species. The USGS also works cooperatively with States to address species of concern to them. This often occurs through the Cooperative Research Units Program established by Congress, in part, for that purpose.

An example of a Federal species of concern is the polar bear, which is protected under the Marine Mammal Protection Act and listed as threatened under the Endangered Species Act. The USGS conducts long-term research on polar bears and their habitat. The goal of current research is to refine scientific models to project the status of polar bears. Much of this research occurs under the Changing Arctic Ecosystems Initiative, which informs resource management decisions for Arctic Alaska with scientific information about ecosystem response to a warming climate.

http://alaska.usgs.gov/science/interdisciplinary_science/cae/index.php 
Developing and adapting new technologies and tools to increase effectiveness, efficiency, safety, and accuracy in answering natural resource management questions.

Environmental DNA (eDNA) is shed from an organism into an environment. It can be detected from water, soil, air, or other non-biological sources within that environment using various molecular techniques. These techniques are widely used to determine if species are present that are rare, nocturnal, invasive, or otherwise difficult to detect, such as manatees, Asian carp, or Burmese pythons. Currently, the USGS is working with industry to develop a fielddeployable eDNA test kit that would allow managers to conduct even quicker, more costeffective surveillance to determine if key species are present. http://pubs.usgs.gov/fs/2012/3146/
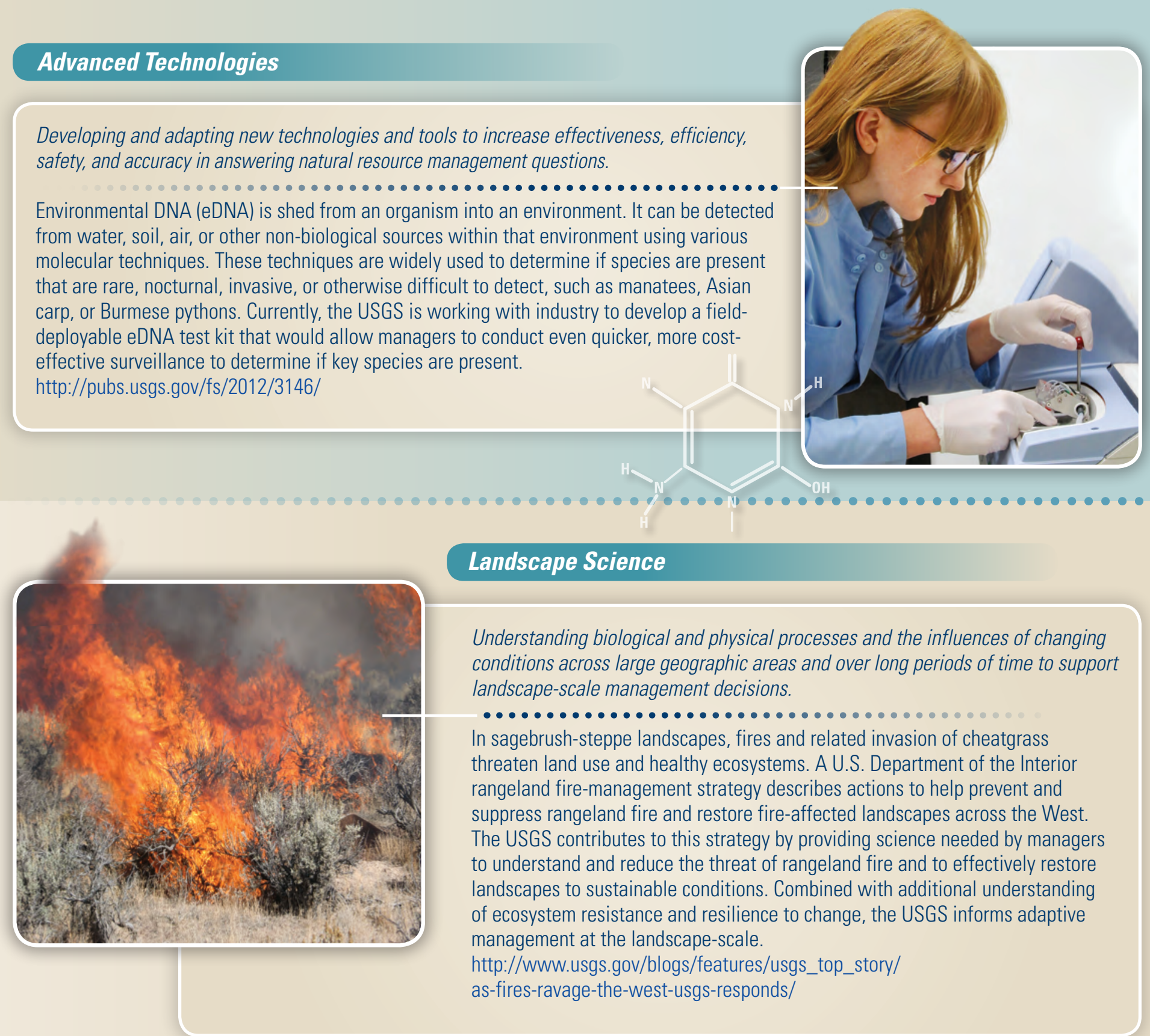

\section{Landscape Science}

Understanding biological and physical processes and the influences of changing conditions across large geographic areas and over long periods of time to support landscape-scale management decisions.

In sagebrush-steppe landscapes, fires and related invasion of cheatgrass threaten land use and healthy ecosystems. A U.S. Department of the Interior rangeland fire-management strategy describes actions to help prevent and suppress rangeland fire and restore fire-affected landscapes across the West. The USGS contributes to this strategy by providing science needed by managers to understand and reduce the threat of rangeland fire and to effectively restore landscapes to sustainable conditions. Combined with additional understanding of ecosystem resistance and resilience to change, the USGS informs adaptive management at the landscape-scale. http://www.usgs.gov/blogs/features/usgs_top_story/ as-fires-ravage-the-west-usgs-responds/

\section{Energy and Wildlife}

Understanding environmental effects of energy development, and developing tools and strategies to assist in responsible development of energy resources while minimizing negative effects to wildlife.

Recent exponential growth in wind-energy capacity has raised concerns about negative effects on wildlife. USGS science helps discover reasons why some flying species, bats for instance, are susceptible to collision with turbines and to develop innovative tools to reduce injury and fatalities. Managers and industry operators now use the statistical tools developed by the USGS to estimate wildlife fatalities at wind facilities. New monitoring protocols and habitat models will provide the basis for understanding how species such as golden eagles could be affected by wind energy development, support permitting and siting of new facilities, and guide potential strategies for mitigation. http://www.usgs.gov/ecosystems/energy_wildlife/

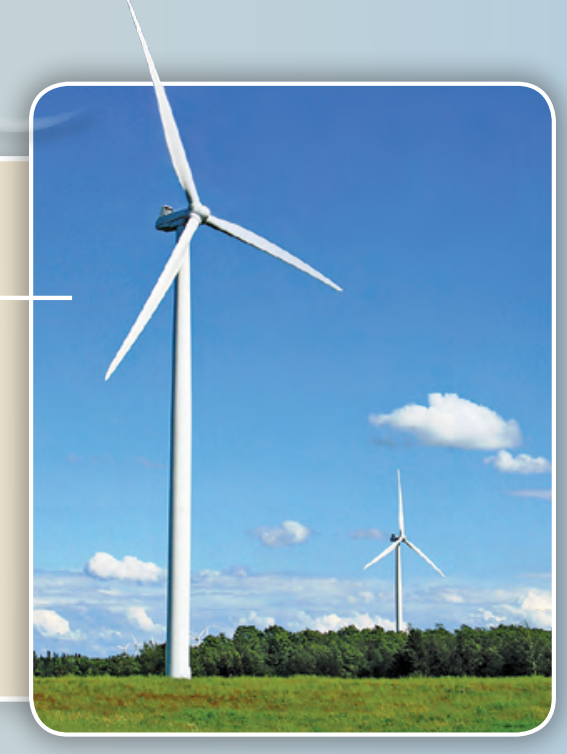




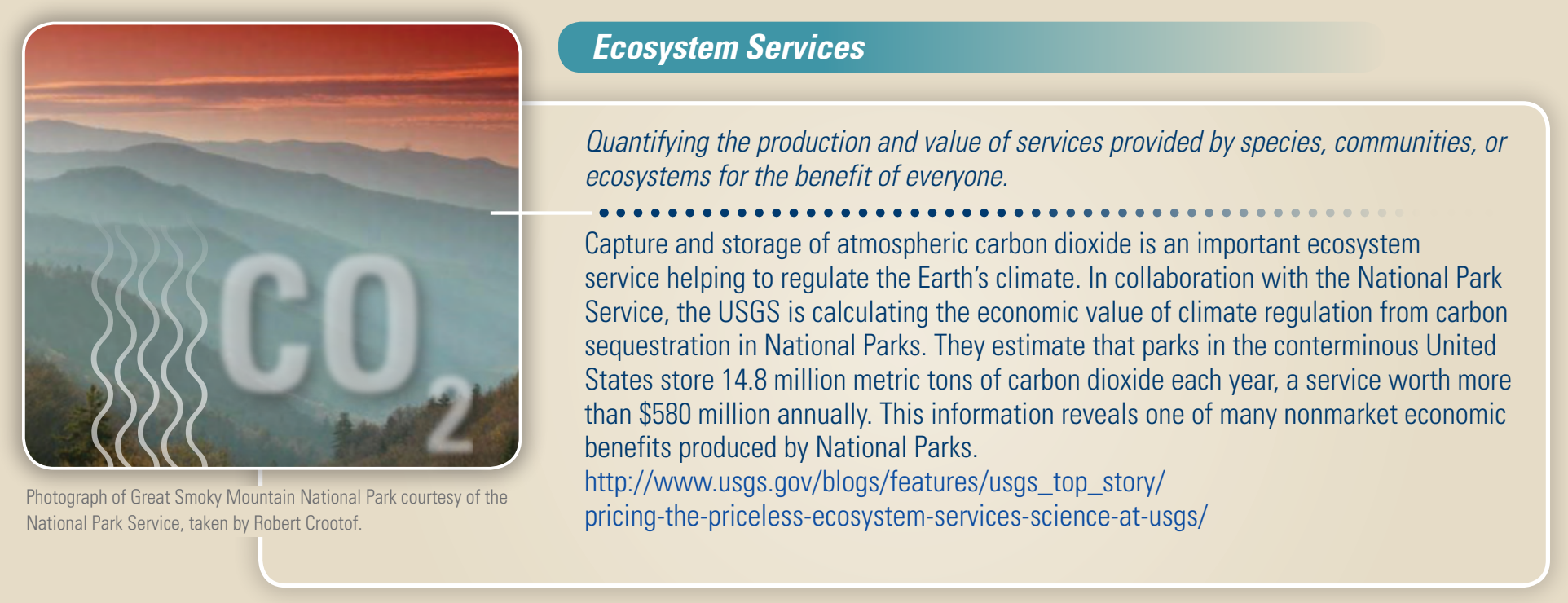

\section{Ecological Flows}

Advancing the understanding of water-flow needs of species or aquatic communities and developing tools to evaluate tradeoffs in water-allocation decisions.

The Delaware River Basin, covering portions of New York, New Jersey, Pennsylvania, and Delaware, provides water to 15 million people and a variety of fish and wildlife. An integrative decision-support system developed by the USGS provides habitat data for key aquatic species, including both sport and migratory fish and federally endangered species. This decision-support system provides useful data for managers who must meet the diverse human and ecological water needs within the basin. http://pubs.usgs.gov/circ/1384/support/c1384.pdf

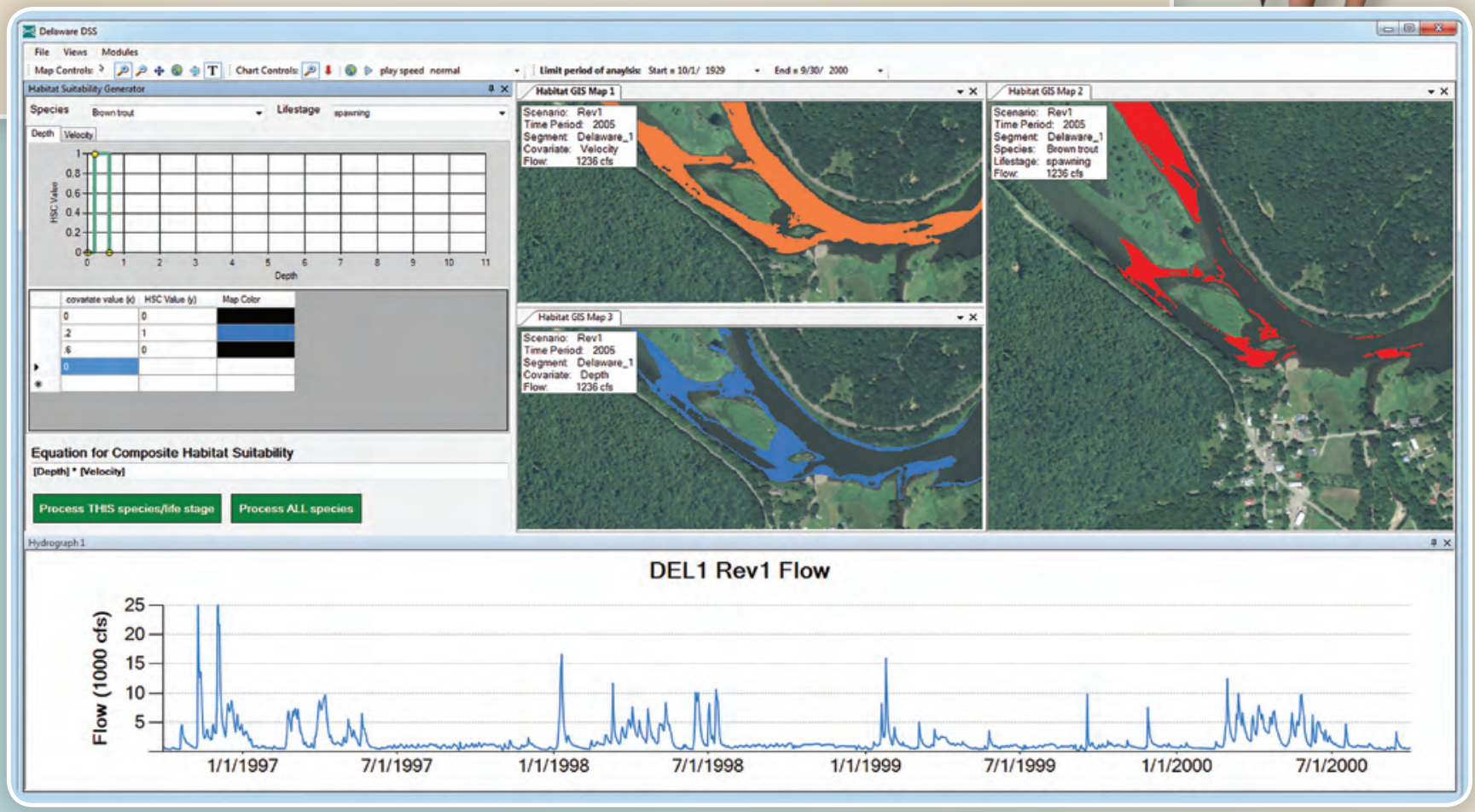




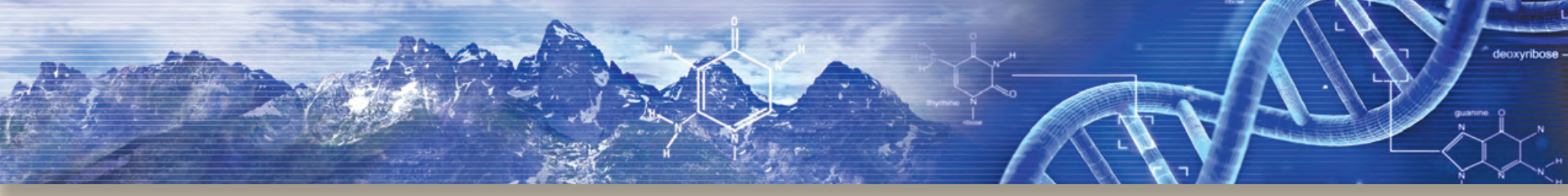

\section{Emerging Diseases and Biosecurity}

Describing the ecology of fish and wildlife diseases, and developing surveillance, control, and risk-assessment tools to support natural resource management and Federal biosecurity efforts.

White-nose syndrome, a fatal fungal infection of hibernating bats, has killed at least 6 million bats since 2006, threatening the survival of vulnerable populations of bats and even some species. The USGS is a national leader in white-nose syndrome research, discovering and understanding the disease in collaboration with partners, and supporting a national plan for managing the disease by developing treatment options. http://www.usgs.gov/blogs/features/usgs_top_story/ trick-or-treat-the-frightening-threats-to-bats-2/
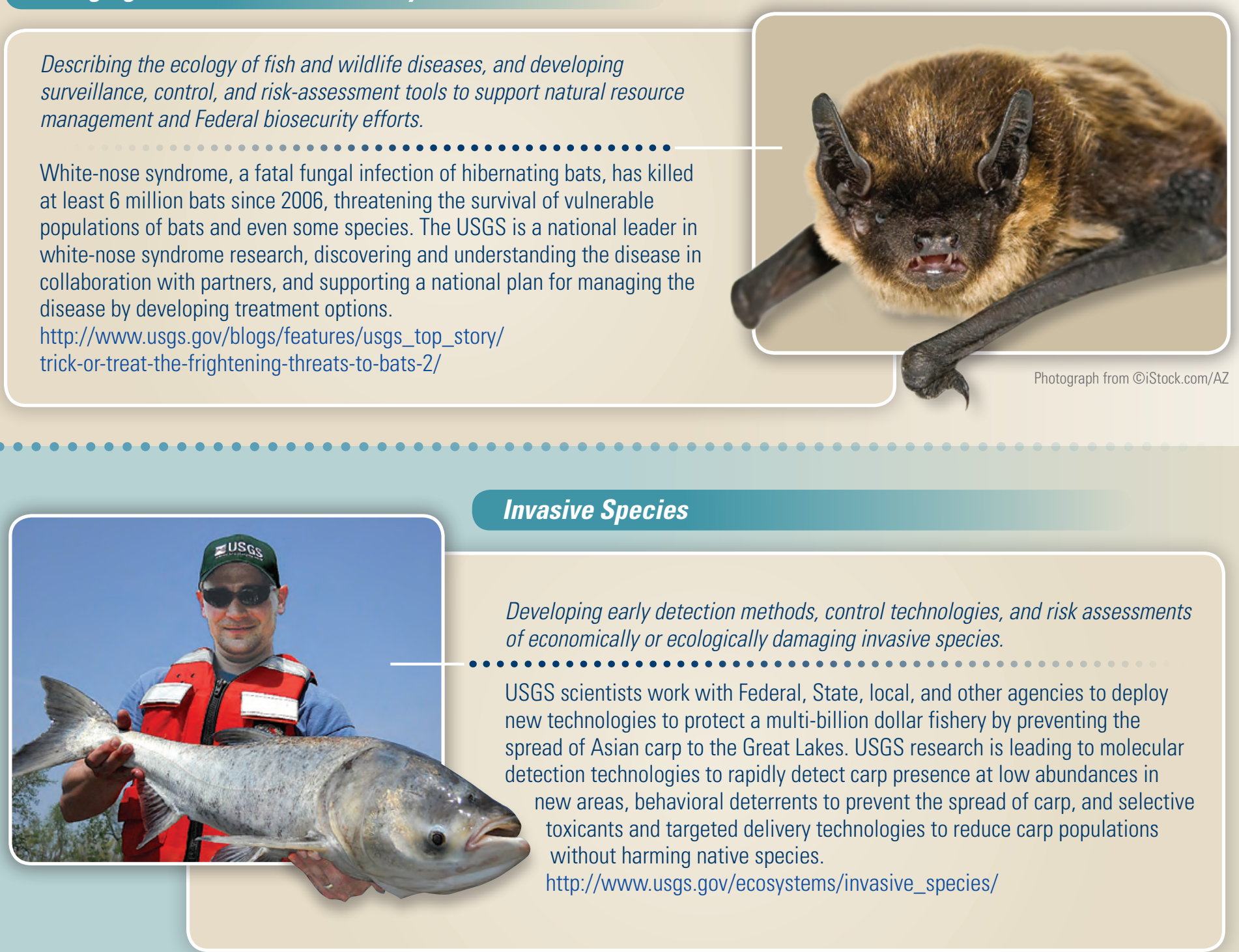

Invasive Species

Developing early detection methods, control technologies, and risk assessments of economically or ecologically damaging invasive species.

USGS scientists work with Federal, State, local, and other agencies to deploy new technologies to protect a multi-billion dollar fishery by preventing the spread of Asian carp to the Great Lakes. USGS research is leading to molecular detection technologies to rapidly detect carp presence at low abundances in new areas, behavioral deterrents to prevent the spread of carp, and selective toxicants and targeted delivery technologies to reduce carp populations without harming native species.

http://www.usgs.gov/ecosystems/invasive_species/

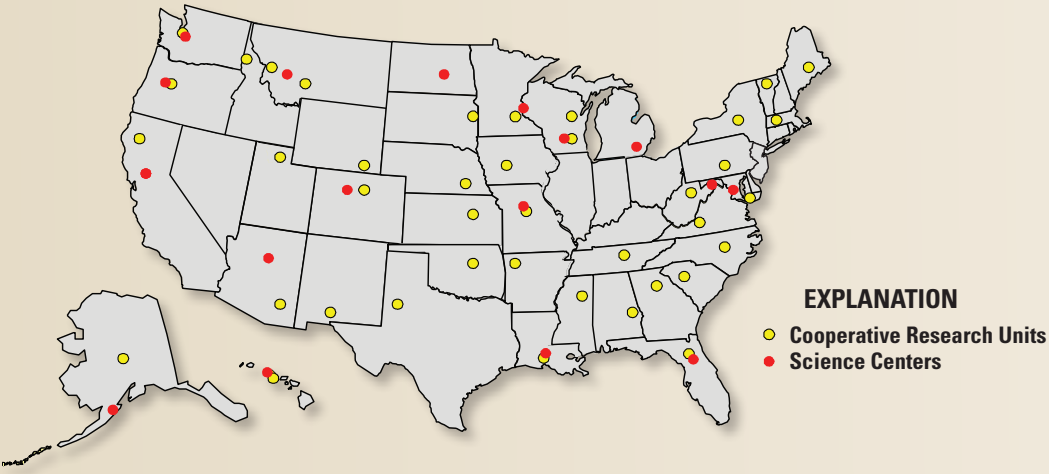

USGS Cooperative Research Units and Science Centers are located throughout the United States. Congress provides funding to the Ecosystems Mission Area through six programs: Cooperative Research Units, Environments, Fisheries, Invasive Species, Status and Trends, and Wildlife.
Author: U.S. Geological Survey

For more information:

Ecosystems Mission Area

http://www.usgs.gov/ecosystems/

http://www.usgs.gov/ask/

1-888-ASK-USGS (1-888-275-8747)

Images used in banner:

DNA image: (CiStock.com/Andrey Prokhorov

Tetons image: (i)iStock.com/aimintang

All other photographs from USGS unless otherwise noted.

Publishing support provided by the U.S. Geological Survey, Science Publishing Network, Tacoma Publishing Service Center Design: Bill Gibbs

ISSN 2327-6916 (print) ISSN 2327-6932 (online) ISSN 2327-6932 (online) 